\title{
Observações sobre as Simetrias e Dissimetrias da Natureza
}

A palavra simetria, que deriva simultaneamente do grego e do latim, está conotada com a disposição harmónica das partes de um conjunto. A ideia mais imediata ou mais corrente de simetria é talvez a de simetria bilateral, também dita sagital, que é aquela que o nosso corpo apresenta e que existe também no corpo de muitos animais. Existe simetria sagital quando o corpo pode ser dividido em duas partes que estão uma para a outra como um objecto está para a sua imagem num espelho. A nossa boca é um órgão ímpar (tal como o nariz) mas é evidentemente constituída por duas metades das quais uma é a imagem especular da outra. O mesmo acontece com o sexo; mas o sexo ocupa um lugar especial porque, para além de possuir a simetria sagital presente na estrutura geral do corpo, ele sugere a alteridade (a relação com o outro) que complica ou perturba a ideia de simetria. Simetria e dissimetria, identidade e complementaridade, são conceitos que se aproximam e confundem no contexto dos fenómenos psíquicos e humanos. Neste contexto a noção de simetria não tem aquele rigor geométrico de correspondência ponto a ponto que possui em diversas ciências exactas. A própria simetria bilateral do corpo humano está longe de ser uma simetria perfeita. Não só porque temos no rosto um sinal do lado direito que não encontra correspondência do lado esquerdo, mas por razões mais diáfanas e profundas. Há alguns anos fascinou-me uma ilustração de um artigo publicado numa revista de psicologia. Tratava-se de um artigo sobre a identificação dos rostos e a ilustração consistia numa fotografia de Margaret Tatcher que tinha uma pequena particularidade: os olhos da fotografia original haviam sido cuidadosamente recortados e recolocados mas na posição inversa. $\mathrm{O}$ resultado era uma verdadeira monstruosidade e o que era perturbante é que era difícil descortinar a razão dessa monstruosidade... A simetria sagital aparente do nosso cérebro (constituído por dois hemisférios enantiomórficos *) é destruída pela lateralização cerebral ou seja pela especialização funcional diferente dos dois hemisférios. E ainda a estrutura do nosso psiquismo, consciente e subconsciente, vigília e sonho, representações diurnas e representações nocturnas, simetria e dissimetria das relações entre essas representações. No plano cultural as simetrias parecem esboroar-se ainda mais. Em todas as civilizações há apenas cerca de $10 \%$ de canhotos ou seja há uma clara predominância da mão direita. E isto tem consequências sociais na medida em que, apesar de o mercado oferecer objectos especificamente fabricados para canhotos (as tesouras Wilkinson p. ex.), a escola pré-primária ainda revela alguma dificuldade na inserção desta minoria. No plano simbólico a esquerda e a direita desempenham também papéis diferentes. $\mathrm{Na}$ China, por exemplo, associa-se a esquerda ao céu e ao Yang ao passo que a direita é associada à Terra e ao Yin.

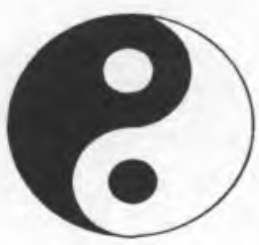

FIGURA

$O$ grande símbolo religioso do Oriente é totalmente assimétrico. As zonas escuras correspondem ao Yin e as claras ao Yang. $O$ Yin e o Yang simbolizam as dualidades fundamentais da vida: beleza e fealdade, bem e mal, masculino e feminino, sol e lua, noite e dia, etc... Os dois pontos significam que nada é perfeito ou seja que um dos aspectos de uma dualidade contém sempre algo do outro. $O$ equivalente tridimensional do símbolo Yin-Yang é a bola de ténis mas a introdução da terceira dimensão eliminou a assimetria. Com efeito a bola de ténis já apresenta uma simetria direito-esquerda.

Mas a simetria bilateral é sem dúvida uma característica da aparência de muitos animais. A operação de simetria que gera essa bilateralidade é uma reflexão num plano e é interessante verificar que esse plano é definido por duas direcções: a direcção vertical e a da locomoção do animal. Por outro lado, os seres vivos com pouca mobilidade ou imóveis parecem não apresentar bilateralidade isto é não têm esse plano de simetria. Pensemos numa flor, num ouriço, numa anémona, numa estrela do mar e verifiquemos a ausência de definição de qualquer plano particular. O que se mantém definida é a direcção vertical (apenas um eixo) o que

* Dizemos que são enantiomórficos dois objectos dos quais um é a imagem especular do outro e que para além disso não são sobreponíveis. Em Química dizem-se enantiómeros duas moléculas que apresentam estas características. Exemplo: as moléculas

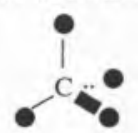

e

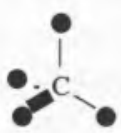

são enantiómeros porque são a imagem especular uma da outra e porque não são sobreponíveis (por mais que rodemos uma delas nunca conseguimos obter algo igual à outra). As moléculas

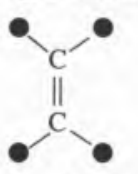

e

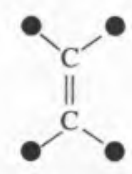

não são enantiómeros mas sim a mesma molécula porque, se bem que a estrutura da esquerda seja a imagem especular da direita, elas são sobreponíveis (basta rodar de $180^{\circ} \mathrm{em}$ torno do eixo $\mathrm{C}=\mathrm{C}$ para se obter a outra).

Departamento de Engenharia Química, Instituto Superior Técnico. 
significa que o animal ou a planta é idêntico a si próprio não por reflexão num plano mas sim por rotação em torno de um eixo.

Continua a haver simetria porque há uma disposição harmónica ou regular de partes semelhantes, mas essas partes não se opõem face a face como num espelho. Elas deduzem-se uma das outras por rotação em torno de um eixo. É de facto interessante verificar que quase todos os seres vivos apresentam alguma simetria que pode, como vimos, ser de natureza diversa. Qual a origem dessa simetria? Trata-se de um problema que poderá estar associado à atracção gravítica, às condições de vida sobre o nosso planeta. A simetria sagital parece estar associada à locomoção. Comparemos uma estrela do mar com um cavalo marinho. Dir-se-ia que a locomoção implica leis biomecânicas particulares que conduzem a uma certa perda de simetria (a simetria axial é mais elevada do que a simetria sagital). Há aliás uma aparente diminuição de simetria à medida que se caminha para a complexidade no mundo dos seres vivos. No limite, a sedução é totalmente assimétrica. A assimetria do sistema nervoso central existe nos primatas a partir de um certo grau de complexidade. Ela pode não estar presente nos pequenos macacos mas é existente nos grandes primatas como o chimpazé, o orangotango e o homem. Do ponto de vista da história paleontológica a origem dessa dissimetria situa-se provavelmente nos australopitecos - primeiros seres da nossa família mas que ainda não são humanos.

A simetria é pois parte da Natureza, algo que é inerente à natureza da vida na Terra porque eventualmente relacionado com a força gravítica. Por outro lado a evolução parece processar-se através de roturas sucessivas da simetria.

No contexto da história da ciência a noção de simetria é antes de mais uma noção geométrica. Os geómetras gregos interessaram-se por figuras que apresentam simetrias de vários tipos. O círculo que é invariante relativamente a qualquer rotação no plano em torno do seu centro. A esfera que o é em relação a qualquer rotação no espaço em torno do seu centro. Outras figuras são invariantes relativamente a algumas rotações mas não a todas (são menos simétricas que o círculo e a esfera). É o caso dos polígonos e poliedros regulares. O pentágono regular, figura rodeada de conotações místicas, reproduz-se igual a si próprio por rotação de $72^{\circ}$ (quinta parte da rotação completa). Existe um número infinito de polígonos regulares dado que existe um número infinito de números naturais. No entanto apenas existem cinco poliedros regulares convexos: o tetraedro regular que tem quatro faces que são triângulos equiláteros; o cubo (seis faces quadradas); o octaedro regular (oito faces triângulos equiláteros); o dodecaedro (doze faces pentagonais regulares); e o icosaedro (vinte faces triângulos equiláteros). Estes poliedros regulares já eram conhecidos dos geómetras gregos. São os chamados «sólidos platónicos» em torno dos quais Platão construiu, no Timeu, a sua teoria cosmológica. Cada um destes sólidos simbolizava um elemento fundamental: fogo (tetraedro), Terra (cubo), ar (octaedro) e água (icosaedro), sendo o dodecaedro (faces pentagonais) o símbolo do Universo.

A simetria tornou-se um conceito matemático em fins do século XVIII com o desenvolvimento da álgebra no domínio da resolução de equações algébricas. Uma equação de grau $n$ tem $n$ raízes que apresentam determinadas propriedades de simetria, que podem ser permutadas. As permutações permitidas dependem da estrutura da equação, dos seus coeficientes. Foi Evaristo Galois (matemático francês que morreu em 1832 com apenas 21 anos) quem elaborou a teoria destas equações algébricas: a chamada teoria dos grupos. A noção de simetria invadiu também a Física. Fenómenos periódicos como o movimento pendular e o movimento da corda vibrante são descritos por funções que apresentam uma simetria particular e o seu estudo pode ser feito pela chamada análise de Fourier. Mas não é apenas nos domínios clássicos da Mecânica, da Acústica ou da Óptica que surge a noção de simetria. Esta domina a Física contemporânea, das partículas elementares à cosmologia. Foi no século XIX com Biot $\mathrm{e}$ Pasteur que a simetria invadiu a Química. Sabemos hoje que a actividade biológica das moléculas depende fortemente da sua simetria e que uma característica fundamental dos aminoácidos que formam as nossas proteínas é a sua assimetria. A noção de simetria permeia pois a ciência contemporânea e manifesta-se aos mais diversos níveis da realidade material, desde as partículas elementares ao Universo no seu conjunto.

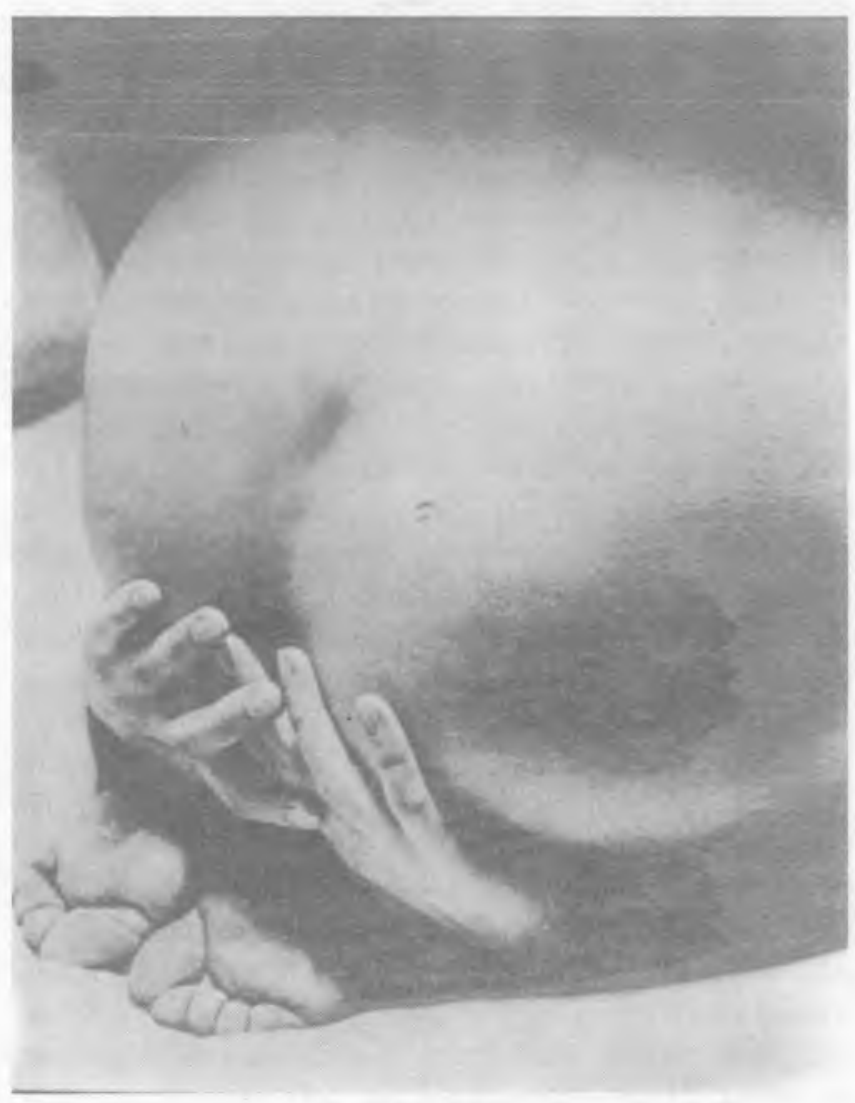

FIGURA 2

Os seres vivos apresentam diversos tipos de simetria. A simetria radial é frequente no mundo vegetal e nos animais invertebrados. A simetria bilateral parece estar associada à locomoção. Nos humanos e nos grandes primatas as bilateralidade do corpo é perturbada pela assimetria do sistema nervoso central. Man Ray, A oração (1930).

\section{A simetria do Universo}

A palavra Univero é uma palavra renascentista que significa que tudo o que existe tem a mesma natureza. Trata-se de um conceito bem característico da ciência moderna e que teve os seus mártires como Giordano Bruno. A luneta de Galileu permitiu descobrir que havia montanhas na Lua como na 
Terra, que havia manchas na superfície do Sol, que Vénus apresentava fases como as da Lua. Daí a ideia da homogeneidade do Universo e da identidade da génese dos astros do céu. $\mathrm{Na}$ Antiguidade céu e Terra tinham naturezas diferentes. O céu era incorruptível; a Terra era corruptível. A metafísica do número sete (sete corpos celestes móveis), sete notas de música, sete dias da semana) envolvia e corporizava a cosmogonia antiga. Para Aristóteles e para os antigos o Universo tinha uma forma esférica mas esta ideia era consequência de uma ilusão de óptica. As observações astronómicas mostram que a Lua se move em torno da Terra e que a Lua e Terra giram, como outros planetas, em torno do Sol; é o Sistema Solar. Por outro lado, o Sol é uma estrela entre muitas na Via Láctea cujo conjunto roda em torno de um centro. Daí a ideia de que um sistema discóide dotado de movimento de rotação se insere, em maior escala, noutro sistema discóide também ele em rotação. Esta ideia deixa no entanto de funcionar quando os astrónomos observam mais longe. Com efeito, a partir de uma distância da ordem dos 100 milhões de anos-luz (as galáxias para além do chamado super-agregado local) não se observa qualquer direcção preferencial de achatamento: existem galáxias em todas as direcções do céu e com a mesma densidade. O panorama é idêntico em todas as direcções o que sugere que o Universo é isótropo, isto é homogéneo em esferas concêntricas. A descoberta por Penzias e Wilson, em 1965, da radiação de fundo isótropa a $2.7 \mathrm{~K}$ reforçou esta imagem do Universo e deslocou drasticamente a balança da teoria do Big-bang em detrimento da teoria do universo estacionário. Apesar de diferirem radicalmente na sua visão do Universo, nenhuma delas prevê para ele qualquer assimetria geral. Existem no entanto assimetrias a níveis mais restritos ou locais. A Terra, por exemplo, para além do seu campo magnético próprio que the confere uma certa assimetria, tem uma forma que não corresponde a um igual achatamento nos dois polos o que significa que de facto a forma da Terra é como a de uma pera ou um pião. Face a um espelho, o pião em repouso tem uma imagem igual a si próprio. Mas se lhe imprimirmos um movimento de rotação surge a assimetria: a imagem no espelho roda no sentido oposto ao do pião real. Para além disso o achatamento desigual gera assimetrias entre os dois hemisférios e tal ocorrerá à superfície de qualquer astro em rotação.

A problemática das origens coloca também problemas de simetria. As cosmogonias antigas descreviam o aparecimento dos seres diferenciados que povoam o mundo como uma quebra de simetria a partir de uma realidade primordial homogénea e infinita. Foi desta quebra de simetria que nasceu o erotismo uma vez que se criou a diferenciação sexual e a atracção que une e gera. $O$ discurso da cosmologia contemporânea apresenta do ponto de vista formal alguns paralelismos com o das cosmogonias antigas: a singuralidade do Big-bang tem óbvias semelhanças formais como o ovo original *. Sabemos hoje em dia que as partículas elementares conhecidas interagem através de quatro tipos de força: a gravitacional, a electromagnética (que é aquela com

\footnotetext{
* Luísa Costa Gomes, Cosmologias e Mitologias, in "A evolução cósmica e a origem da vida", H.L.S. Maia e J.J. Moura Ramos eds., Livraria Almedina, Coimbra, 1985.
}

que a Química lida e que é responsável pelas reacções químicas e pela estabilidade dos átomos e moléculas), a forte e a fraca. Terão estas forças uma essência diferente ou poderão elas ser unificadas num princípio único do qual se poderia deduzir a racionalidade do mundo? Uma das actividades centrais da Física contemporânea é a busca da «supersimetria» que unificaria as quatro forças. De acordo com o «modelo standard» (outro nome com o qual se designa o modelo do Big-bang) a força gravítica, a que opõe maior resistência à unificação, é também o actor principal na história física «recente» do Universo. Este sofre actualmente um processo de expansão que é travado pelo efeito gravitacional. No início era o Big-bang. Nele reinaria a supersimetria ou seja só existiria uma única força, uma superforça chamada supergravidade. Ao longo da expansão e do arrefecimento, porém terão ocorrido uma série de roturas de simetria que espartilharam a superforça nas quatro forças que hoje conhecemos. Mas como compreender as condições iniciais do nosso Universo, a causa da grande explosão, a natureza da supersimetria? Há quem tente explicar a origem do nosso Universo como resultado de flutuações do «vazio quântico» *. Segundo este modelo a matéria ter-se-ia formado irreversivelmente a partir do espaço-tempo por intermédio de mini-buracos negros e nesse processo teria havido uma explosão de entropia. Para este modelo o processo seria irreversível, não havendo lugar para um eventual retrocesso da expansão do Universo e a assimetria do tempo seria consequência da génese do Universo.

\section{A simetria nas partículas elementares}

Nenhuma teoria cosmológica prevê, como vimos, qualquer assimetria geral no Universo ou, por outras palavras, o Universo parece não manifestar qualquer preferência pela esquerda ou pela direita, o Universo parece ser aquiral **. O Universo é invariante relativamente à operação de reflexão num espelho e esta invariância exprime-se por uma lei de conservação que é a chamada lei de conservação de paridade. Apesar da complexidade desta problemática e de ela não ser de fácil acesso para nós químicos, as suas implicações são fáceis de compreender: a conservação da paridade significa que todas as forças que operam nas interacções entre partículas são desprovidas de qualquer tendência esquerda ou direita. Isto não quer dizer que não encontremos assimetrias dos mais diversos tipos no Universo. Quer apenas dizer que a natureza funcionaria tão bem à direita como à esquerda. A Terra descreve na nossa galáxia uma trajectória helicoidal e portanto assimétrica, mas haverá outros planetas cuja trajectória será a hélice inversa. A lei da conservação da paridade não estipula que as duas formas enantiomórficas de uma estrutura assimétrica devam existir em igual quantidade. Afirma apenas que não existe nada nas leis da natureza que impeça a existência dos dois enantiómeros. No entanto, à escala das

\footnotetext{
* O problema do vácuo ou do vazio (ausência de matéria) pareceria à primeira vista ser um problema pacífico para as ciências exactas. Tal não acontece no entanto e o/a leitor/a interessado/a poderá ler com agrado o artigo de David Polarski, Les énigmes du vide, publicado em La Recherche n. ${ }^{2} 219$, pg. 372 , Março de 1990.

** Quiral significa assimétrico e portanto não sobreponível com a sua imagem especular.
} 
partículas elementares esta conservação da paridade está hoje em dia posta em causa como veremos adiante.

Para nós químicos a matéria é constituída por protões, neutrões e electrões. Para os físicos estas partículas são combinações de partículas elementares, os quarks, e a cada partícula corresponde uma anti-partícula em tudo igual à partícula excepto no facto de ter propriedades conservativas (carga, momento magnético) opostas. A primeira anti-partícula descoberta foi o positrão que é semelhante ao electrão mas com carga positiva (Carl David Anderson, 1932) embora a existência de anti-partículas já tivesse sido prevista por Paul Adrien Maurice Dirac, um dos maiores físicos e matemáticos de todos os tempos. Da colisão de uma partícula com uma anti-partícula resulta eliminação de matéria e produção de energia (fotões). Uma vez descobertas as anti-partículas correspondentes às partículas de matéria ordinária (o protão, o neutrão e o electrão) os físicos passaram a interrogar-se sobre a existência de anti-matéria. Um átomo de antihidrogénio seria constituído por um anti-protāo no núcleo e por um positrão que gravitaria em torno dele. E de processo análogo de constituiriam os outros elementos. Existiriam galáxias de matéria como a nossa e galáxias de anti-matéria. Da eventual colisão apenas restaria radiação. Na constelação Cisne existem duas galáxias que parecem interpenetrar-se e que emitem uma radiofrequência anormal. Há quem pense tratar-se de uma colisão entre uma galáxia e uma anti-galáxia e há também quem não acredite nisso. A passagem à ficção científica já está feita há muito tempo e história de amores frustrados entre um rapaz e uma anti-rapariga já foram contadas de várias maneiras. Mas apesar de não ter ainda sido possível produzir no laboratório um anti-átomo é importante compreender que a existência de anti-matéria não viola a lei da paridade, não indica qualquer escolha preferencial por parte da natureza pela direita ou pela esquerda. Será que uma partícula e uma anti-partícula poderão ser consideradas como enantiómeros? Seráa que por exemplo a diferença entre uma carga positiva e uma carga negativa poderia ter algo a ver com uma estrutura espacial assimétrica da própria partícula? Será que o estudo da estrutura do electrão permitirá no futuro a descoberta de uma assimetria espacial equivalente àquela que levou os químicos do século XIX a mostrar que os isómeros ópticos de Pasteur eram de facto imagens um do outro no espelho?

Até 1956 não se conhecia nenhuma experiência que demonstrasse a violação da lei da paridade. Foi nessa altura que surgiu a grande perturbação designada por «mistério tetatau» e que conduziu à consciência de que não havia conservação da paridade ao nível das partículas constituintes da matéria. Foram Lee e Yang, dois jovens físicos de origem chinesa, quem deram a sugestão, baseada numa análise cuidada dos resultados de experiências envolvendo interacções fracas, de que estas interacções não conservaram a paridade ou seja que elas eram capazes de distinguir entre esquerda e direita. Coube a uma mulher, também de origem chinesa, de nome Chien-Shiung Wu, conceber e realizar a experiência decisiva. Esta dizia respeito à desintegração beta do isótopo 60 do cobalto. Desintegração beta significa emissão de electrões e estes são emitidos pela interacção fraca pelos poros norte e sul do núcleo. Como em condições de temperatura relativamente elevada e na ausência de campos
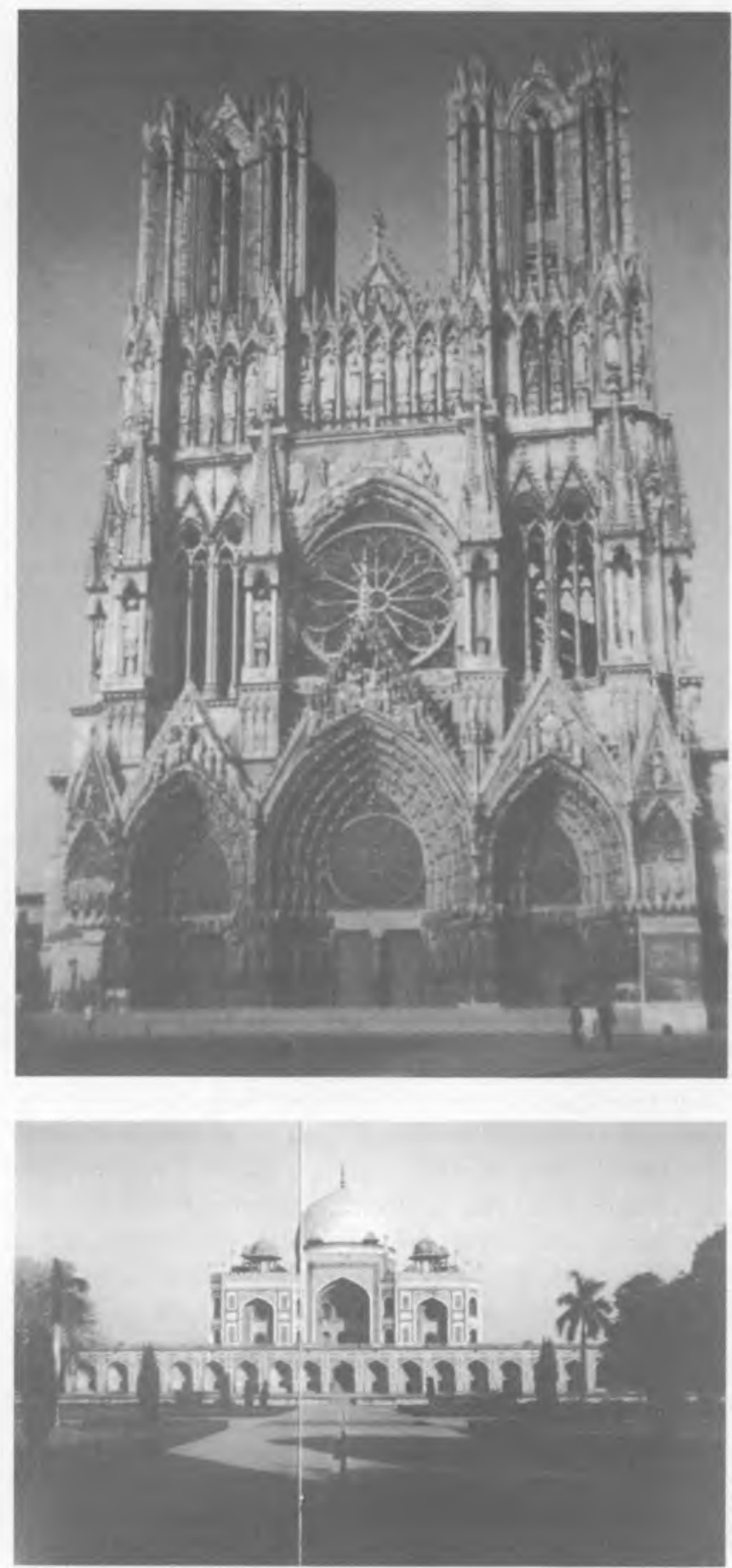

FIGURA 3

A simetria tem obviamente uma grande importância em arte e em arquitectura. A simetria bilateral está presente na arquitectura religiosa de todas as civilizações. Esta bilateralidade possui um forte poder emocional. Ao instituir um eixo privilegiado que atravessa o monumento ela carrega-o de significações simbólicas que conduzem à sacralizaçâo. A arte religiosa contém ideias de auto-suficiência e de permanência ou imutabilidade que the são conferidas pela simetria bilateral. A bilateralidade parece pois necessária para simbolizar a divindade e os palácios seculares, por muito grandiosos que sejam, nunca apresentam este tipo de simetria (o palácio dos Doges, em Veneza, é exemplo deste ponto de vista). A simetria axial, por outro lado, rodeia os lugares santos nas cúpulas dos altares principais das catedrais. A estrutura fractal ascendente das catedrais góticas (ver catedral de Reims apresentada na figura) afirma a elevação. Esta série de bifurcaçōes em que o número de elementos aumenta em altura ao passo que as suas dimensōes diminuem imprime um movimento ascendente tal como acontece com os ramos de uma árvore. A simetria fractal descendente dos templos e mausoléus islâmicos (ver na figura o mausoléu de Humayun, Dehli, 1560) transmite pelo contrário a ideia de enraizamento do monumento conferindo-lhe uma estabilidade harmoniosa que o torna eterno. 
orientadores a orientação do eixo do núcleo é aleatória, os electrões são emitidos em todas as direcções. Wu pensou que seria interessante criar condições em que o eixo do núcleo do cobalto 60 tivesse um alinhamento preferencial com uma dada direcção e observar se a quantidade de electrões emitida pelos dois polos era igual. Para isso realizou a experiência a temperatura muito baixa, próximo do zero absoluto para eliminar tanto quanto possível o efeito uniformizador da agitação térmica, e aplicou um campo magnético para dar ao eixo do núcleo uma orientação preferencial. Mediu a intensidade de electrões emitidos segundo a direcção do polo norte e sul do campo magnético aplicado e verificou a assimetria que tantos físicos negavam mas que Yang e Lee haviam previsto. A experiência foi repetida por outros laboratórios e os resultados foram confirmados. Não nos cabe não teríamos aliás competência para tal - explicar de forma aprofundada as consequências desta descoberta para a ciência contemporânea. Mas elas são certamente imensas o que explica a atribuição do prémio Nobel da Física a Lee e Yang em 1957 com 30 e 34 anos de idade, respectivamente. Aquilo que nos interessa daqui reter é que o electrão é assimétrico (quiral) e que a natureza produz preferencialmente um dos enantiómeros. A investigação neste campo não podia parar e mais recentemente, em 1983, verificou-se que nem só a interacção fraca era violadora da paridade, mas que o mesmo acontecia também com a interacção electrofraca (a interacção resultante da unificação teórica entre a interacção electromagnética e a fraca). Esta questão toca-nos directamente dado que é a interacção electromagnética que é responsável pela ligação dos electrões aos núcleos e pela ligação dos átomos no seio das moléculas. Com efeito a evolução do conhecimento neste campo poderá iluminar o obscuro problema da origem da quiralidade molecular dos organismos vivos terrestres.

\section{A simetria nas moléculas}

Os alunos de Licenciatura em Química ou Engenharia Química estão familiarizados com o problema do efeito da simetria molecular sobre as propriedades macroscópicas de um conjunto de moléculas, em particular sobre a entropia. Se considerarmos um gás constituído por moléculas esféricas e se imaginássemos que tirávamos fotografias ao sistema em vários instantes, essas fotografias não nos permitiriam ter a percepção da rotação das moléculas. Isto porque uma esfera é igual a si própria quando roda em torno de qualquer eixo. Pelo contrário, se as moléculas do gás forem totalmente assimétricas as fotografias seriam todas diferentes porque um objecto assimétrico é sempre diferente quando fotografado de ângulos diferentes. E a termodinâmica estatística demonstra que a entropia do gás é tanto maior quanto maior for o número de fotografias diferentes (microstados) ou seja quanto menor for a simetria. Por outro lado a simetria das moléculas afecta a sua interacção com a radiação de baixa frequência (radiofrequências ou microondas) que é a gama sensível aos movimentos rotacionais das móléculas. Mas o problema mais tipicamente químico e mais fascinante em relação com a simetria molecular é o problema da quiralidade das moléculas e biomoléculas. Já vimos que um objecto ou uma molécula se diz quiral se não for sobreponível com a sua imagem num espelho plano. O exemplo que é costume dar-se imediatamente é o da mão e isto poderá ter uma explicação antropológica. A mão terá sido, segundo os antropólogos, um órgão cujo desenvolvimento teve um papel importantíssimo na evolução que conduziu ao homo sapiens, e quem sabe se não guardamos algures o registo desse facto. A mão é também, e talvez por isso, um centro irradiador do nosso erotismo. Ora a imagem no espelho da mão esquerda é a mão direita a ambas são não-sobreponíveis. Uma mão é um objecto quiral e um par de mãos (direita e esquerda) são enantiómeros. Os nossos pés também são enantiómeros. Dois enantiómeros são objectos muito parecidos e no entanto todos conhecemos manifestações da quiralidade na vida quotidiana: calcem-se os sapatos ao contrário e não tardará a termos uma consciência dolorosa da realidade da quiralidade. As diferenças entre dois enantiómeros são muito subtis e por isso nem todos os métodos físicos ou químicos são capazes de distinguir entre uma dada molécula e o seu enantiómero. Por exemplo, a massa molar, o ponto de fusão ou de ebulição, o momento dipolar, são propriedades rigorosamente iguais para os dois enantiómeros e consequentemente a sua medida é incapaz de os discriminar. E também são iguais os seus espectros rotacionais (radiofrequências, micro-ondas), vibracionais (infra-vermelho) e electrónicos (ultra-violeta ou visível), Para distinguir enantiómeros é necessário usar métodos físicos ou químicos muito selectivos. Tal como uma meia, calça bem os dois pés, sendo portanto incapaz de os distinguir, ao passo que um sapato já é capaz de o fazer. Pode também acontecer que uma dada técnica seja capaz de distinguir dois enantiómeros em determinadas condições (de temperatura, por exemplo) mas já não o consiga noutras condições.

A semelhança entre dois enantiómeros é tão grande que não é fácil para os químicos sintetizar substâncias quiralmente puras (apenas um dos dois enantiómeros). O resultado dessas sínteses é geralmente uma mistura em iguais proporções do objecto esquerdo e direito (chamada mistura racémica). Pelo contrário a Natureza viva só produz um dos enantiómeros isto é faz uma opção clara entre esquerda e direita. Os aminoácidos do nosso organismo são moléculas quirais e o organismo produz essas moléculas quiralmente puras. $\mathrm{O}$ mesmo acontece no mundo vegetal. Um exemplo é o da essência de terebintina que é retirada do pinheiro: determinados pinheiros produzem apenas um dos enantiómeros, outros produzem o enantiómero oposto.

\section{As estruturas isoméricas e a classificação das suas relaçōes}

Chamamos isómeros a moléculas que apresentam a mesma composição atómica, a mesma fórmula molecular. Por exemplo, o álcool etílico e o éter metílico têm ambos a mesma fórmula molecular: $\mathrm{C}_{2} \mathrm{H}_{6} \mathrm{O}$. Trata-se no entanto de substâncias diferentes, com propriedades físicas diferentes (temperatura de ebulição, energia de vaporização, momento dipolar, etc...). Dizemos que estas duas substâncias são isómeros estruturais (mesmos átomos mas ligados entre si de maneira diferente). Em oposição chamamos homómeros a «duas substâncias» cujas moléculas são congruentes (são exactamente iguais) e portanto dois homómeros 'são uma única 
substância. Por outro lado, chamamos estereoisómeros àqueles isómeros que diferem apenas por razões estereoquímicas ou seja pela forma como os átomos se dispõem no espaço. Os estereoisómeros são idênticos relativamente ao tipo de ligações e à ordenação destas no seio da molécula, mas diferem no arranjo espacial dos átomos. Um exemplo de estereoisómeros é o cis e o trans dicloroetileno:<smiles>ClC=CCl</smiles>

cis<smiles>ClC=CCl</smiles>

trans
Ambas as moléculas possuem uma ligação dupla carbonocarbono, duas ligações $\mathrm{C}-\mathrm{H}$ e duas $\mathrm{C}-\mathrm{Cl}$ mas diferem no arranjo espacial dos átomos. Outro exemplo será<smiles>FC(Cl)Br</smiles>

(a)

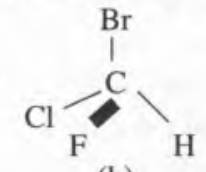

(b)
Estas duas moléculas são também diferentes no arranjo espacial dos átomos: se olharmos segundo $\mathrm{Br}-\mathrm{C}$ no sentido dos ponteiros do relógio vemos $\mathrm{HClF}$ em (a) e $\mathrm{HFClem}$ (b). Os exemplos (1) e (2) são exemplos de estereoisómeros. No entanto, no exemplo (2) as moléculas, não sendo iguais, apenas diferem pelo facto de uma ser a imagem da outra num espelho plano o que não acontece nas moléculas do exemplo (1). A estes estereoisómeros que são a imagem especular um do outro chamamos enantiómeros. As moléculas que, como as do exemplo (2), têm um carbono assimétrico (ligado a quatro átomos ou grupos diferentes) são quirais e podem apresentar-se sob a forma de dois enantiómeros. Como vimos dois enantiómeros são constituídos por moléculas muito parecidas ao ponto de apresentarem um grande número de propriedades idênticas. Pelo contrário, os estereoisómeros como os do exemplo (1) têm propriedades diferentes e a este tipo de estereoisómeros cuja relação entre si não é a de um objecto com a sua imagem especular chamamos diastereoisómeros. É assim que todos os livros de Química Orgânica apresentam a classificação das relações entre estruturas isoméricas. Esta classificação baseia-se na especificação da conectividade entre os átomos e pode ser esquematizada da seguinte maneira:

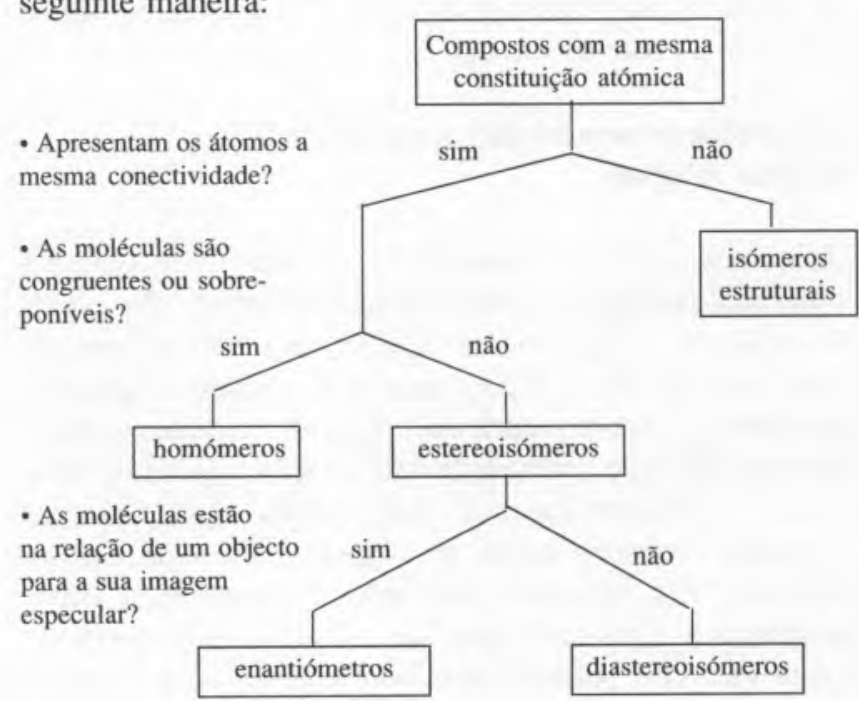

Esta classificação não apresenta ambiguidades e é aceite ao nível das regras de nomenclatura. No entanto é aparente que ela apresenta uma falta de harmonia, uma assimetria notável. Isto do ponto de vista formal. Porque por outro lado, em termos mais de conteúdo, ela induz uma distinção ou separação entre diastereoisómeros e isómeros estruturais que é pouco satisfatória na medida em que os diastereoisómeros se assemelham mais aos isómeros estruturais (em ambos os casos trata-se de entidades químicas diferentes com propriedades físicas e reactividades diferentes) do que aos enantiómeros. Para além disso os enantiómeros (que não são discerníveis em meio aquiral e cujas propriedades escalares são idênticas) assemelham-se mais aos homómeros do que aos diastereoisómeros.

Kurt Mislow da Universidade de Princeton, utilizou a teoria dos grafos para prôpor uma outra classificação baseada na relação de equivalência de isometria (em vez da conectividade como era o caso da classificação convencional). Uma isometria é uma operação que preserva os comprimentos dos segmentos que unem pares de pontos, isto é que preserva o tamanho e a forma da figura. Podemos distinguir uma isometria de primeira espécie: produto de um número par de reflexões (identidade, rotação ou translacção, rotação e translacção) e uma isometria de segunda espécie: produto de um número ímpar de reflexões (reflexão, rotação e reflexão). A nova classificação surge então da seguinte forma:

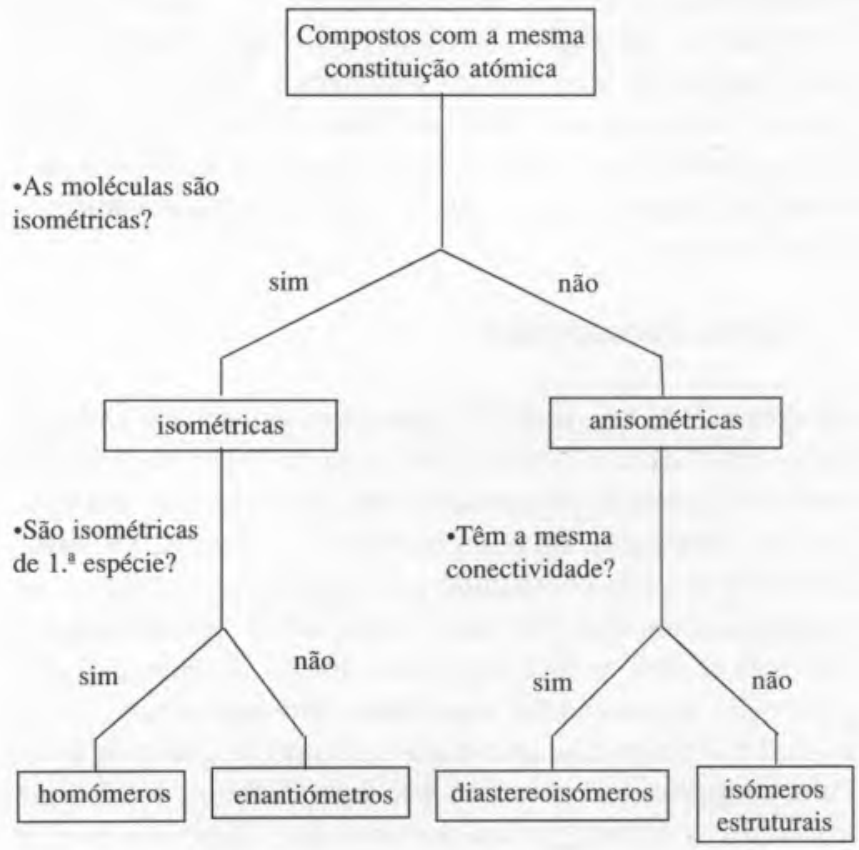

Esta classificação não apresenta, tal como a classificação convencional, qualquer ambiguidade e tem talvez a vantagem de repôr no seu lugar a harmonia e o significado físico das coisas...

O problema da quiralidade foi descoberto no início do século XIX pelo químico francês Jean-Baptiste Biot ao verificar que o quartzo se apresentava sob duas formas que tinham a propriedade de rodar em sentidos opostos o plano de polarização da luz. A matéria constituída por moléculas simétricas, ou os cristais com uma estrutura reticular simétrica, não têm qualquer acção sobre o plano de polarização da luz (este 
plano é o mesmo antes e depois da luz atravessar a amostra). $\mathrm{O}$ mesmo acontece com uma mistura racémica (dois enantiómeros misturados em idênticas proporções). Mas uma substância quiralmente pura faz rodar esse plano e por isso se diz opticamente activa *. Foi Pasteur quem relacionou a actividade óptica que algumas substâncias revelam com a sua quiralidade. O/a leitor/a interessado/a em aprofundar este domínio fascinante da quiralidade em Química encontrará na bibliografia sugestões interessantes e modernas.

Se duas moléculas enantioméricas são muito parecidas, se as suas subtis diferenças apenas podem ser detectadas por métodos muito específicos, essas subtis diferenças têm contudo consequências imensas em Química e em Bioquímica. Tentaremos ilustrar, através de dois exemplos, a importância da quiralidade na acção bioquímica das moléculas. O primeiro é o da anfetamina que é um estimulante que actua sobre os neurónios do sistema límbico de forma a aumentar a capacidade dos neurotransmissores para comunicar entre si através das sinapses. A acção bioquímica destas moléculas realizase por interacções destas com as moléculas do neurotransmissor (neste caso a noradrenalina), interacções estas que são fortemente dependentes da forma molecular. O mecanismo actuante é do tipo «chave-fechadura» ou «mão-luva» implicando uma forte complementaridade das moléculas que interagem. Este tipo de complementaridade é uma exigência de muitos mecanismos bioquímicos, desde a síntese das proteínas e dos ácidos nucleicos até aos mecanismos sensoriais como o gosto e o olfacto. A molécula de anfetamina cuja estrutura é

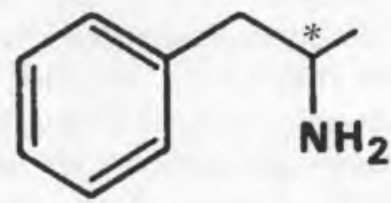

apresenta um carbono assimétrico (marcado por um asterisco) e por isso é quiral. Apresenta-se, pois, sob a forma de dois enantiómeros cujas estruturas moleculares diferem como diferem as nossas duas mãos. Verifica-se que a forma direita (que roda o plano de polarização da luz no sentido dos ponteiros do relógio) é um estimulante muito mais forte do que a forma esquerda o que significa que é a forma direita que melhor se encaixa na molécula específica do neurotransmissor. Isto mostra que o problema da quiralidade está longe de ser um problema de interesse apenas teórico ou académico. O outro exemplo é o da talidomida que é um sedativo e hipnótico suave que foi comercializado na Europa em 1956. Tinha a vantagem de não ser letal mesmo quando consumido em grandes doses. No entanto, veio a verificar-se que a talidomida induzia deformações genéticas em crianças cujas mães haviam ingerido esse medicamento durante os primeiros meses de gravidez. A talidomida é uma molécula com a estrutura

* Esta rotação pode fazer-se em dois sentidos opostos: o sentido dos ponteiros do relógio ou o seu oposto. Se um dos enantiómeros roda esse plano num sentido, o outro roda-o em sentido oposto. Por isso se fala em molécula direita ou esquerda para referir dois enantiómeros.

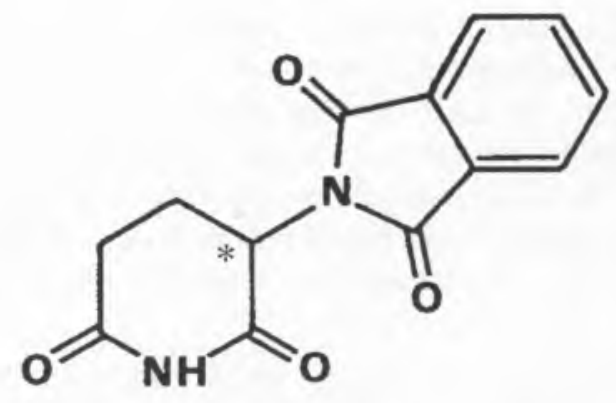

que apresenta um carbono assimétrico e é portanto quiral. Sabe-se hoje que só a forma direita da talidomida provoca modificações genéticas. O medicamento comercializado era uma mistura racémica e é essa a razão do desastre que foi a utilização da talidomida como medicamento.

O subtil problema da quiralidade levanta também questões fundamentais a que a ciência ainda não consegue dar resposta. Porque é que os organismos vivos produzem substâncias quiralmente puras ao passo que os químicos só conseguem produzir no laboratório misturas racémicas? Porque é que o pinheiro de Bordéus produz a essência de terebintina «esquerda» ao passo que o pinheiro de Alep produz a essência «direita»? Porque é que os aminoácidos das nossas proteínas são todos «esquerdos»? Qual é a origem da quiralidade ou, por outras palavras, o que é que levou, nọ processo evolutivo, a haver uma preferência da Natureza por um dos enantiómeros? O avanço da Física no domínio das interacções fracas poderá vir a contribuir para esclarecer estas interrogações. Se a interacção electrofraca distingue entre esquerda e direita, os átomos e moléculas até agora considerados como aquirais poderão apresentar uma certa forma de quiralidade. É cada vez mais evidente que o mundo em que vivemos é quiralmente assimétrico em todas as escalas. $\mathrm{E}$ isto remetenos para a questão final que é a da assimetria do tempo.

\section{A simetria do tempo}

As sociedades arcaicas (babilónios, egípcios, iranianos...) não suportavam a carga do desenrolar do tempo, não se sujeitavam à irreversibilidade. Elas sentiam a necessidade de se renovar periodicamente através da anulação do tempo e da renovação da cosmogonia, o que corresponde a uma intenção anti-histórica, a uma vontade de desvalorizar o tempo *. Esta recusa da irreversibilidade dá origem à elaboração de concepções cíclicas de que os mitos «lunares» são exemplo. É o regresso cíclico do que aconteceu anteriormente, o «eterno retorno». Ao atribuir ao tempo uma estrutura cíclica os homens das sociedades arcaicas aboliam a sua irreversibilidade. O passado não passava então de uma prefiguração do futuro. $\mathrm{O}$ tempo, que possibilita o aparecimento e a existência das coisas, deixa assim de ter qualquer influência decisiva sobre os acontecimentos. Esta concepção cíclica do tempo é tipicamente antropomórfica (existe de facto um tempo biológico cujo ritmo é modulado pelas idades da vida, pela evolução orgânica). Mas o que é facto é que nem a gota de água de um rio, nem a vida social, podem subir o «curso do tempo» que é de facto descendente. $\mathrm{O}$ filme da evolução não é cíclico

\footnotetext{
* Mircea Eliade, O mito do eterno retorno, Edição 70, Lisboa (1988).
} 
nem sequer reversível. O que não quer dizer que não existam localmente processos cíclicos ou reversíveis desde que se desenvolvam num meio que thes forneça as energias susceptíveis de lhes conferir esse carácter. Não será o sentimento de impotência sentido pelo homem face à assimetria do tempo que explica a sua vontade obstinada de reencontrar o paraíso perdido, de se reincarnar ou reintegrar a sua matriz original?

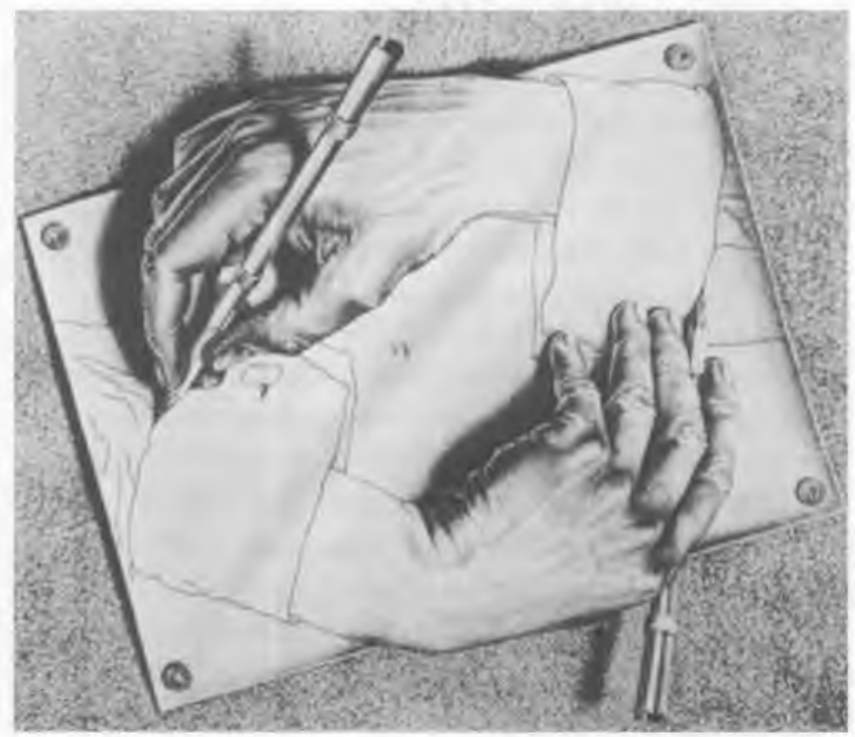

FIGURA 4

M.C. Escher, Desenhar (1948). Nesta litografia de Escher representam-se duas mâos cada uma delas com um lápis que desenha a outra. $O$ acto de desenhar prossegue indefinidamente. A vida é criada e mantida através desta referência circular que nâo é propriamente uma autoreferência na medida em que as duas mãos sâo diferentes: uma é esquerda, a outra direita. Contrariamente ao que acontece em muitos trabalhos de Escher nāo existe aqui qualquer paradoxo.

Os seres humanos adaptam-se às variações periódicas do meio ambiente. Os ritmos circadianos (de período próximo do dia) existem em todos os organismos vivos excepto nas bactérias. Mas os ritmos biológicos não se limitam às periodicidades circadianas. No caso do homem eles regulam a actividade do coração e a dos neuronas que controlam a respiração e a actividade cerebral. Se estes ritmos não existissem teríamos nós a sensação da passagem do tempo? A maioria dos ritmos biológicos são endógenos isto é resultam de processos que se desenrolam no seio do organismo e não de variações periódicas do meio ambiente, e a sua propriedade mais marcante (em Química, como em Física ou em Biologia) é o facto de constituirem fenómenos de autoorganização no tempo. Para além do carácter cíclico característico de qualquer ritmo, ele subentende um dado sentido de rotação que é a manifestação da seta do tempo associada a qualquer fenómeno irreversível. Este sentido de rotação observa-se em vários domínios: em ecologia no ciclo presapredador, assim como nas reacções autocatalíticas associadas aos ritmos bioquímicos. Daqui poderia emergir uma noção helicoidal do tempo (nem cíclica, nem linear) que conciliaria a irreversibilidade com a existência dos ritmos cósmicos e biológicos. Mas dado que uma hélice é um objecto quiral, imediatamente surgiria o problema de saber se o tempo é uma espiral esquerda ou direita. Deixemos pois de lado esta problemática e sublinhemos apenas que a ontogénese dos ritmos no processo de evolução é um dos domínios mais importantes no contexto da compreensão do problema da origem da vida e que neste contexto se desenvolveram investigações importantes de que se salientam os trabalhos de Manfred Eigen. O conhecimento dos ritmos biológicos tem para além disso importância no aparecimento de novas terapêuticas e deu mesmo lugar a uma nova área da farmacologia, a chamada cronofarmacologia. Um exemplo de novas terapêuticas surgidas neste contexto situa-se na área da endocrinologia. É sabido que a secreção de hormonas (insulina, hormona de crescimento, etc...) pelos organismos se faz periodicamente. Experiências realizadas em animais permitiram demonstrar que o ritmo hormonal só exerce o seu efeito se tiver o período apropriado (um período errado é tão ineficaz como o estímulo permanente). Estas observações permitiram tornar férteis mulheres estéreis devido a perturbações da secreção hormonal através da injecção periódica da hormona apropriada.

Não existe como vimos incompatibilidade entre a existência de ritmos biológicos e a seta do tempo. No entanto, a visão estática do mundo que nega a irreversibilidade ou considera o devir como uma ilusão remonta à origem da ciência ocidental com o célebre paradoxo de Zenão de Eleia (a flecha que nunca chegará ao termo da sua trajectória). Para Newton o tempo tinha uma realidade absoluta e para ele o fluir do tempo ocorreria mesmo num Universo privado de mudança física ou química. Apesar desta sua concepção as equações da mecânica newtoniana, como aliás as da relatividade e da mecânica quântica, não implicam que o tempo passa ou seja são invariantes relativamente à inversão do tempo $(\mathrm{t} \rightarrow-\mathrm{t})$. Para Kant, que muito apreciava a obra de Newton, o tempo não tinha qualquer realidade. A permissa básica da sua «estética transcendental» era que as coisas não são mais que representações das nossas percepções sensoriais e têm origem no nosso aparelho psíquico. Nesta concepção o tempo não é inerente aos objectos ou coisas, não é algo objectivo, mas pertence essencialmente ao funcionamento da mente. As propriedades das coisas em si, os «nómenos», só podem ser estudadas e conhecidas através dos seus «fenómenos» que são os reflexos ou imagens dos nómenos na nossa esfera. Não podemos conhecer o mundo tal como é mas apenas a nossa maneira de nos apercebermos dele. Ao projectarmos a nossa consciência do tempo no mundo exterior limitamo-nos a transferir para os sistemas físicos uma lógica que não passa de um disfarce de percepção.

Para Einstein a passagem do tempo era encarada como simples resultado da consciência sem qualquer contrapartida objectiva. No contínuo do espaço-tempo da relatividade restrita os acontecimentos não se desenvolvem, são, pura e simplesmente. Para sublinhar o carácter subjectivo do tempo Einstein diria nas suas aulas: «Se você estiver acompanhado por uma mulher muito bonita, duas horas parecem-lhe dois minutos, numa situação penosa dois minutos podem parecer duas horas. É isto a relatividade». A nossa percepção do passado, do presente e do futuro seria uma ilusão subjectiva, resultado da fraqueza da nossa mente. $\mathrm{O}$ que existe é o espaço-tempo indivisível e estático. No espaço-tempo o tempo não tem autonomia; os acontecimentos não acontecem, são. Tal como o espaço é constituído por locais, o espaço- 
tempo é constituído por acontecimentos. A sensação de que o tempo corre é uma ilusão. As equações da relatividade são invariantes relativamente à inversão do tempo: futuro e passado desempenham o mesmo papel. As trajectórias seguidas pelos átomos ou pelas partículas que constituem o nosso Universo podem ser indiferentemente traçadas no sentido do futuro ou do passado. Os físicos e os químicos sabem no entanto que este tipo de descrição não é aplicável a todos os fenómenos. Todos sabemos que dois líquidos miscíveis colocados no mesmo recipiente se difundem para formar uma mistura homogénea. $\mathrm{O}$ facto de, uma vez misturados, não se observar a separação espontânea dos dois líquidos evidencia a unidirecionalidade do tempo. Por outro lado, a existência de fenómenos complexos, e a imprevisibilidade que resulta dessa complexidade, empresta à noção de tempo uma nova luz. Com efeito um dos objectivos da ciência é o de conseguir uma previsão da evolução futura dos sistemas naturais a partir do seu estado presente e de observações efectuadas no passado. A mecânica newtoniana mostra espantosamente que este programa pode, em certos casos, ser levado a cabo com enorme precisão. É isso que permite aos astrónomos calcular com precisão a data dos eclipses passados e prever a passagem futura dos cometas conhecidos. No entanto, o tempo que faz hoje nem sempre corresponde àquele que os metereologistas haviam previsto e isto traduz a existência de fenómenos que podemos qualificar de «complexos» cujo estado futuro não se pode deduzir do seu presente através de um algoritmo simples e reprodutível. A previsibilidade perfeita de um fenómeno simples como o movimento pendular ou o movimento planetário reduz o tempo à categoria de parâmetro matemático ordinário. Pelo contrário, a imprevisibilidade e a evolução permanentemente renovada de um fenómeno complexo faz do tempo um factor criador no sentido em que o conhecimento do passado deixa o futuro em aberto. Este tipo de fenómenos temporalmente orientados esteve durante muito tempo excluído da descrição fundamental da ciência, sendo considerados como resultado de condições iniciais «improváveis». Hoje em dia são objecto de atenção crescente em vários domínios da ciência.

Como vimos a Física está directamente confrontada com problemas de assimetria espacial ao nível das partículas elementares. Sabe-se agora que pelo menos uma dessas partículas, o neutrino, apresenta provavelmente uma estrutura espacial assimétrica. O problema de saber se o próprio espaço não apresenta uma assimetria intrínseca é hoje em dia discutido por físicos e matemáticos, e isto contrariando a visão da Física Clássica e relativista assim como da mecânica quântica que descrevem o espaço como perfeitamente isótropo. Como é que a Física contemporânea encara o problema da assimetria do tempo? Esta questão remete-nos para um teorema de simetria fundamental da Física que é o chamado teorema PCT. P significa paridade (esquerda ou direita), C significa carga (positiva ou negativa) e $\mathrm{T}$ significa tempo (directo ou retrógrado). O teorema PCT afirma que se num processo natural se verificam as três inversões (da paridade, da carga e do tempo), então o processo resultante pode ocorrer na Natureza e é indiscernível do processo original. A inversão PCT de um sistema consistiria na reflexão num espelho da estrutura espacial, na inversão de todas as cargas (dando origem ao anti-sistema) e na inversão do sentido do movimento das partículas. Quando se descobriu a quebra de paridade nas interacções fracas a surpresa foi grande mas a simetria global do Universo parecia ter sido restabelecida pela descoberta de que a quebra de paridade deveria ser acompanhada pela inversão da carga. Os físicos chamam espelho PC a um espelho imaginário que inverte simultaneamente a paridade e a carga. Nos anos 60 um grupo de físicos da Universidade de Princeton chegaram no entanto à conclusão, ainda a partir de experiências envolvendo interacções fracas, de que o espelho PC não restabelece a simetria do Universo, ou seja que quando há inversão da paridade e da carga o processo resultante não é exactamente a réplica do processo original. A aceitação deste enunciado teria grandes implicações pois significaria que para preservar a simetria PCT seria necessário pôr de parte a ideia da invariância relativamente à inversão do tempo. Os físicos consideram que as provas acumuladas no laboratório apontam para uma assimetria temporal, se bem que esta não seja observada directamente. Não existe prova directa da impossibilidade de um micro-acontecimento se desenvolver ao contrário. Sabese que a simetria PC é quebrada em determinadas interacções e, para que a simetria PCT seja conservada, é necessário postular uma assimetria do tempo.

Parece pois existir uma seta do tempo inerente aos processos físicos mesmo à escala microscópica. E no entanto as leis fundamentais da Física (das mecânicas clássica, relativista e quântica) são reversíveis isto é são invariantes relativamente à substituição de t por - t. Ao nível macroscópico a seta do tempo está sempre presente e o seu sentido é constante no funcionamento do nosso espírito: recordamos o passado mas não temos recordações do futuro. Mas não é só na nossa consciência que a seta do tempo tem um sentido bem definido. À escala macroscópica o Universo está recheado de acontecimentos que nunca fazem marcha atrás. A seta do tempo é um elemento do mundo exterior e não um resultado da nossa consciência. As crateras da Lua guardam informações sobre a sua história e são obviamente mais recentes que a própria Lua. Terra e Lua são mais jovens que o Sol e este é mais jovem que a nossa galáxia. Tal como a superfície da Lua, as células do nosso cérebro guardam as marcas do passado: o sentido da seta do tempo do nosso espírito é o mesmo do da seta do tempo do mundo exterior. O devir não é uma visão do espírito mas sim algo que é inerente à Natureza. Mas se as lei fundamentais da Física são reversíveis o que é que faz com que o movimento da Natureza se faça em sentido único? A resposta parece residir nas leis das probabilidades. Alguns acontecimentos ocorrem num único sentido não porque a sua ocorrência em sentido oposto seja impossível mas porque ela é extremamente improvável. E isto é uma característica dos sistemas constituídos por um grande número de partículas como é o caso dos sistemas macroscópicos. Quando um grande número de objectos interactuam de forma aleatória a probabilidade empresta ao tempo um sentido único. Seria um milagre que os biliões de biliões de moléculas de um sistema macroscópico passassem a comportar-se de forma a inverter o curso dos acontecimentos. É pois nas leis probabilísticas que encontramos a origem da seta do tempo, são as probabilidades que explicam processos aparentemente tão irreversíveis como a mitura de café 
com leite, a quebra de um vidro por uma pedra e muitos outros acontecimentos familiares unidireccionais que envolvem um grande número de moléculas. O Sol emite radiação; nunca veremos a energia convergir de todas as direcções para se concentrar no Sol para aí se realizarem os processos nucleares inversos que fariam dele um poço de energia em vez da fonte que ele é na realidade.

Ludwig Boltzmann, físico austríaco do século XIX e pai da termodinâmica estatística, foi dos primeiros cientistas a reflectir sobre a explicação, através de leis estatísticas, da ordem do nosso Universo. Para ele a entropia está na base da orientação do tempo macroscópico (a seta do tempo aponta no sentido do aumento da entropia) e os afloramentos locais de ordem no Universo (diminuição local da entropia) resultariam de flutuações aleatórias. A seta do tempo nos processos de complexificação parece ter o sentido inverso da seta da entropia.

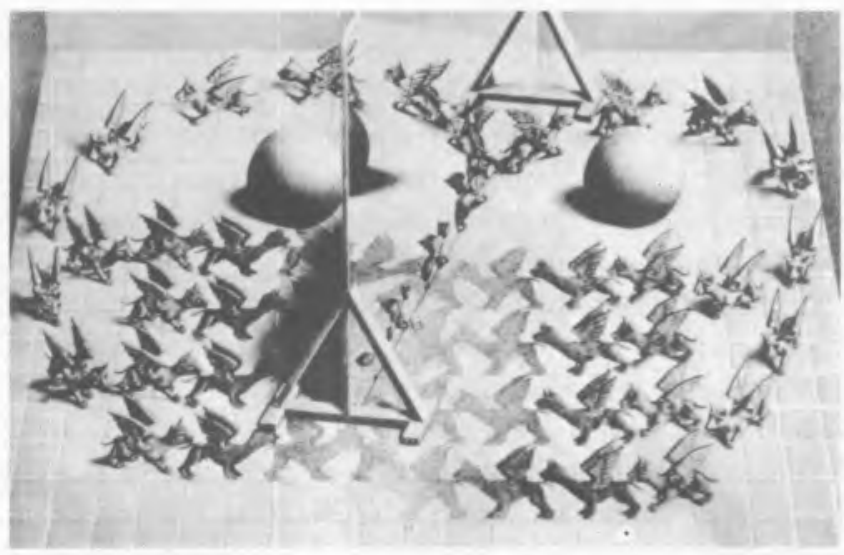

FIGURA 5

Para Escher a pluralidade do mundo nāo significa caos mas sim ordem e realiza-se através da interacçāo entre estruturas e motivos identificáveis. A concepção pluralista do mundo, encarado na sua ordenação e como desafio à descoberta de novas relações lógicas entre os fenómenos, assim como a inseparabilidade, explícita na sua obra, entre estrutura e narração deram a Escher uma forte reputação nos meios científicos. Daí a ampla utilização dos seus trabalhos na ilustraçāo de livros e artigos científicos nos mais diversos domínios, da matemática à física das partículas, passando pela química e pela cristalografia. $O$ conceito de simetria foi muitas vezes um ponto de partida frutuoso em ciência como em arte e para Escher a simetria foi certamente uma fonte principal de inspiraçẩo. M.C. Escher, $O$ espelho mágico, litografia (1946).

\section{Inconclusões}

A assimetria releva-se aos mais diversos níveis do Universo, desde o nível microscópcio das partículas elementares ao nível macroscópico do Universo no seu conjunto. Podemos pois dizer que a assimetria parece uma característica inerente à natureza das coisas. É no entanto difícil articular as diferentes assimetrias que surgem aos diversos níveis. Qual será a relação entre o sentido preferencial do tempo revelado ao nível das interacções fracas entre partículas e a seta entrópica, a seta da expansão universal ou a da nossa consciência? Qual a relação entre a assimetria espacial das partículas elementares e a quiralidade das moléculas biológicas? E em que medida é que a assimetria das moléculas estará relacionada com a bilateralidade do corpo de um macaco ou com a bissexualidade? O Universo está em expansão e não se sabe se ele contém a quantidade de matéria suficiente para que o espaço-tempo se feche. Se isto acontecesse a tendência expansionista inverter-se-ia mas não sabemos se isso teria alguma consequência sobre a paridade ou o sentido do tempo à escala microscópica ou se isso inverteria as setas do tempo à escala macroscópica.

A simetria é cómoda como dizia Montesquieu (essai sur le goût dans les choses de la Nature et de l'Art). "A simetria agrada à alma porque lhe poupa a dor, porque a alivia". Mas por outro lado a simetria pode associar-se ao tédio, à repetição, à acomodação. Hoje em dia a simetria não é critério de beleza para um quadro ou uma poesia. O século XX foi palco da rotura das simetrias sagradas em Arte como em Ciência. À beleza assimétrica de um quadro de Van Gogh opõe-se a futilidade simétrica dos sub-produtos das "artes" decorativas ou publicitárias.

Como sublinhava Roland Barthes em La chambre claire os redactores da Life recusaram fotografias de Kertész porque as imagens falavam "demais"; faziam reflectir, sugeriam um sentido (para além da letra). Não eram imagens de um tempo estático como são as fotografias da publicidade. Dir-se-ia que são as assimetrias do Universo que constroem a sua harmonia.

\section{Bibliografia}

O/a leitor/a interessado/a em se deleitar por caminhos mais profundos nesta fascinante problemática da simetria lerá com agrado o livro:

- La symétrie aujourd'hui, Col. Points, Editions du Seuil, Paris (1989), que é constituído por um conjunto de entrevistas a investigadores das mais diversas áreas, desde a psicanálise à física das part 'culas, passando pela antropologia, a musicologia e as artes visuais. Mas sobretudo não poderá deixar de ler o interessantíssimo livro de Martin Gardner em que largamente me baseei para escrever este texto:

- The ambiedextrous Universe, Penguin Books (1982), ou em edição francesa,

- L'Univers ambidextre, Coll. Science Ouverte, Editions du Seuil, Paris (1985).

Numa perspectiva mais Química, mais voltados para o problema da quiralidade molecular, aconselha-se a leitura dos seguintes artigos:

- Biomolecular handedness, Stephen Mason, Chem. Brit., p. 538, Junho de 1985.

- Biomolecular homochirality, Stephen Mason, Chem. Soc. Rev. 17, 347 (1988).

- The handedness of the Universe, R.A. Hegstrom e D.K. Kondepudi, Sci. Am. p. 98, Janeiro de 1990.

- Origens da quiralidade molecular, R.A. Hegstrom, Bol. Soc. Port. Quím. n. ${ }^{\circ}$ 19 (Série II), p. 35, Março de 1985. 